\title{
EFFECT OF HORMONAL ECG TREATMENT VERSUS REARING-FASTING PROGRAM ON EMBRYO RECOVERY, REPRODUCTIVE PERFORMANCE AND HORMONAL PROFILE IN NULLIPAROUS RABBIT DOES
}

\author{
G.M.K. Mehaisen* and A.O. Abbas \\ Department of Animal Production, Faculty of Agriculture, Cairo University, Egypt \\ *corresponding author email: gamoka7@agr.cu.edu.eg
}

\section{SUMMARY}

The aim of this study was to determine the effect of hormonal eCG treatment versus rearing-fasting program on embryo recovery, reproductive performance and hormonal profile in nulliparous rabbit does. Does at 14 weeks old were randomly divided into three groups according to the estrus synchronization method before insemination; does fed ad libitum (control), does treated with subcutaneous 50IU of eCG $60 \mathrm{~h}$ before insemination (eCG), and does fasted 3 days per week (57\% of feed ad libitum) then fed ad libitum one week before insemination $(r-F P)$. In 23 of receptive does, serum estradiol-17 $\beta\left(E_{2}\right)$ and leptin concentrations were determined at the time of insemination, and then embryos were recovered post-mortem at $72 \mathrm{~h}$ postinsemination. A total of 51 receptive does were used to analyze the reproductive performance of all groups. The sexual receptivity and number of corpora lutea significantly increased in eCG group, however, high incidence of hemorrhagic follicles were observed. A significant increase in embryo recovery and donor rates was found in $r$-FP group compared with control, while no differences were observed in the number of normal embryos recovered per donor doe. The rate of embryos recovered in blastocyst stage significantly decreased in eCG group when compared with r-FP or control groups. The pregnancy rate, kindling rate and number of born alive were significantly higher while gestation duration and number of stillborn were significantly lower in $r$-FP does than those treated with $50 \mathrm{IU}$ eCG. Serum $E_{2}$ and leptin concentrations significantly increased in r-FP does in comparison with other groups. The global productivity of weaned rabbits in receptive does was significantly higher in r-FP than in eCG group. Results indicated that in conditions of this experiment, rearing-fasting program followed by one week feed flushing before the first insemination of rabbit does improves embryo recovery, reproductive performance and related hormones secretion. These results need to be confirmed in a larger scale and several reproductive cycles before recommending that method as an efficient biostimulation for estrus synchronization in nulliparous rabbit does.

Keywords: eCG, rearing-fasting program, embryo recovery, reproductive performance, hormonal profile, rabbit

\section{INTRODUCTION}

One of the main problems in cryoconservation of oocytes and embryos of farm animals is establishing an abundant source of oocytes and, consequently, embryos. Treatments with Pregnant Mare Serum Gonadotropin (PMSG or eCG) are used in rabbit does to induce superovulation ( $>50 \mathrm{IU})$ to ensure the maximum number of normal embryos recovered per donor (Tsiligianni et al., 2004, Mehaisen et al., 2005 and Mehaisen et al., 2006) or to induce estrus (10-40 IU) before artificial insemination (Theau-Clément, 2007). The number of receptive does, kindling rate and the number of weaned rabbits per insemination, as well as the number of corpora lutea in ovulating does and survival embryos increased when eCG injected at 8-25 IU to primiparous and multiparous rabbit does (Theau-Clément et al., 2008a and 2008b). However, Alabiso et al. (1994) did not show any improvement of fertility when the injected eCG increased from 20 to $40 \mathrm{IU}$, especially in nulliparous rabbit does. In addition, Theau-Clément et al. (2008c) reported that the use of PMSG in routine (20-25 IU, 48 hours before insemination) of lactating does at 11 days post-partum durably increases the percent of receptive does at insemination and, as a consequence, their productivity without an important immune risk of anti-eCG antibodies production. On the other hand, the administration of higher dosage of
eCG than 50IU results in an increase in the ovulation rate and the number of recovered embryos, but it also causes various problems such as an increase in the number of hemorrhagic and cystic follicles and a decrease in the quality of recovered embryos (Mehaisen et al., 2005). The routine use of high doses of eCG in subsequent inseminations of rabbits decreased the fertility due to the possible increase in anti-gonadotropin antibodies in treated rabbits (Mehaisen et al., 2006 and Viudes De Castro et al., 2009). Moreover, hormonal treatments are not well accepted by consumers because its residues maybe left in the meat (Castellini, 1996).

Theau-Clément (2000) started an important discussion about the use of non-hormonal biostimulation methods based on physiologic considerations to improve sexual receptivity of does at the moment of insemination and consequently their fertility and productivity. She concluded that lighting programs, dam-litter separation and feeding programs should be interesting ways for synchronization of the reproductive cycle in rabbit does; easy to apply, inexpensive and consistent with animal welfare. The effect of feed restriction and fasting programs was studied by many authors as biostimulation methods in rabbit does (Eiben et al., 2001; Rommers et al., 2001; Rodriguez De Lara, 2002; Gómez et al., 2004 and Brecchia et al., 2006). Most of authors concluded 
that does under fasting showed poor receptivity, fertility and kindling rates when compared with does fed ad libitum. It is clearly demonstrated that food programs are likely to depress reproductive performance (Fortun-Lamothe, 1998), in contrast, few studies lead to the proposal of a program capable of improving sustainable, reproductive performance without depressing the growth of rabbits (Gosalvez et al., 1995, Maertens, 1998, Brecchia et al., 2004 and Brecchia et al., 2006). Only Luzi et al. (2001) improved the fertility and productivity of rabbits by administering an energy flushing (2\% propylene glycol in drinking water) 4 days before insemination. Food flushing after a period of restriction could successfully replace the hormonal use to enhance sexual receptivity and reproductive performance, at least in young rabbits. Bonnano et al. (2004) found that nutritional flushing following a restricted feeding in young rabbit does resulted in improvement of their reproductive efficiency at first $\mathrm{AI}$ and enhancing both embryo recovery rate and number of total born per female. Brecchia et al. (2006) reported that nutritional challenges consisted in re-feeding rabbits on normal diet 1-2 days before AI after 24-48 hours of fasting.

Nutrition and reproduction relation is established by means of certain endocrine signals that communicate nutritional status of female to hypothalamus-pituitary axis (Boiti, 2004). The nutritional status and fasting of rabbit does greatly influenced fertility, metabolic and reproductive hormones (Brecchia et al., 2006). Hormones, such as LH, estradiol-17 $\beta$, insulin, T3 and corticosterone are known to regulate ovulation rate, follicle development and embryo survival (Brecchia et al., 2004). Leptin, a hormone produced by the adipose tissue and an important component of the energy balance regulation, also have a role in the steroidogenesis of pre- and post-ovulatory follicles as well as in early developmental stages of blastocyst (Cunningham et al., 1999 and Zerani et al., 2004).

The aim of this study was to determine the direct effects of hormonal eCG treatment versus rearingfasting program on embryo recovery, reproductive performance and hormonal profile in nulliparous rabbit does.

\section{MATERIALS AND METHODS}

\section{Animals and experimental design:}

A total number of 119 nulliparous New Zealand White (NZW) rabbit does at 14 weeks old and $2150 \pm 58 \mathrm{~g}$ average body weight were used in this study. Does were housed in a semi closed rabbitry housing system and kept in batteries of individual cages $(60 \times 50 \times 35 \mathrm{~cm})$ supplied with feeding hoppers made of galvanized steel sheet and nipples for automatic drinker. The experiment was performed during January - March, 2012 and the ambient minimum and maximum temperatures recorded during this period was $6^{\circ} \mathrm{C}$ and $20^{\circ} \mathrm{C}$, respectively. A commercial concentrate pellets ration was introduced to does throughout the experiment $(89.8 \%$ dry matter
(DM); containing $18.4 \%$ crude protein, $3.1 \%$ ether extracts, $12.7 \%$ crude fiber and $8.5 \%$ ash).

The does were randomly allocated into one of the following three groups according to fasting program and hormonal treatment before the first insemination which applied at 18 weeks old: (1) control group $(\mathrm{n}=39)$, does were fed ad libitum till the first insemination; (2) eCG group ( $n=34)$, does were fed ad libitum and treated with 50IU of eCG hormone subcutaneously $60 \mathrm{~h}$ before the first insemination; (3) r-FP group ( $\mathrm{n}=46)$, does were fasted 3 days per week (57\% of ad libitum feed) during rearing period (3 weeks) then allowed to feed ad libitum one week before the first insemination. Sexual receptivity was evaluated for each group on the day of AI by vulva color (females with only pink or red vulva were considered as receptive does). Only receptive does in each group were artificially inseminated with $0.5 \mathrm{ml}$ of semen previously examined for more than $70 \%$ motile sperm and immediately injected muscularly with $\mathrm{GnRh}(0.8 \mu \mathrm{g}$ of Buserelin acetate, Receptal, Egypt) for ovulation.

\section{Embryo recovery:}

In 23 receptive does, embryos were recovered post-mortem at $72 \mathrm{~h}$ post-insemination. Does were killed and the reproductive tract was immediately removed. Embryos were recovered by perfusion of each oviduct with $5 \mathrm{ml}$ followed by perfusion of each uterine horn with $15 \mathrm{ml}$ of Dulbecco's phosphate buffered saline (DPBS, Sigma) containing 0.2\% of bovine serum albumin (BSA, Sigma). Presumptive embryos were scored by morphological criteria. Only embryos in compact morulae or young blastocyst stage without morphological abnormalities in mucin coat, zona pellucida and embryo cells were catalogued as normal embryos. The number of recent corpora lutea on both ovaries, the number of hemorrhagic follicles (large follicles with blood and diameter $>1.5 \mathrm{~mm}$ ), the recovery rate (oocytes + normal embryos + abnormal embryos/ number of corpora lutea), the number of normal embryos recovered in receptive does, the embryo donor rate (the percentage of donor does with at least one recovered normal embryo from receptive does) and the blastocyst rate (the percentage of normal embryos recovered in blastocyst stage) were recorded for all groups. The global efficacy of embryo recovery (in vitro productivity index $=$ number of normal embryos/ receptive treated does) was calculated for each group.

\section{Reproductive performance:}

A total of 51 receptive does were allowed to complete the gestation period after AI. The reproductive performance of all groups was compared based on the pregnancy rate (the percentage of positive palpations in receptive does), the kindling rate, the gestation duration, and the number of born alive, stillborn and weaned kits per donor doe. The global efficacy of reproduction (in vivo productivity index $=$ number of weaned rabbits/receptive treated does) was calculated for each group. 


\section{Hormonal profile}

Serum estradiol-17 $\beta \quad\left(E_{2}\right)$ and leptin concentrations were measured in the same embryo donor does for each group during 15 minutes of $\mathrm{AI}$ as previously described by Arias-Âlvarez et al. (2010). Briefly, blood samples were collected from the marginal ear vein into non-heparinized tubes and centrifuged at $1200 \mathrm{x} \mathrm{g}$ for $10 \mathrm{~min}$ at $4^{\circ} \mathrm{C}$, and then serum was separated and stored at $-20^{\circ} \mathrm{C}$ until analyzed.

Serum $E_{2}$ and leptin concentrations were measured at hormonal assay labs (Cairo University Research Park) by ELISA reader (BIO TEK ELX808) using ELISA kits (EIA-2693 for $E_{2}$ and EIA-2395 for leptin, DRG International, Inc., USA). For both $\mathrm{E}_{2}$ and leptin assay, aliquots from calibrator one were done as a serial dilution to adjust standard curve to rabbit values. For $\mathrm{E}_{2}$, the intra- and interassay coefficient of variations was $6.8 \%$ and $7.2 \%$, the analytical sensitivity was calculated as $2.5 \mathrm{pg} / \mathrm{ml}$ and the dynamic range of the assay was $2.5-500$ $\mathrm{pg} / \mathrm{ml}$. For leptin, the intra- and inter-assay coefficient of variations was $5.9 \%$ and $11.5 \%$, the analytical sensitivity was $0.5 \mathrm{ng} / \mathrm{ml}$ and the dynamic range of the assay was $0.5-25 \mathrm{ng} / \mathrm{ml}$.

\section{Statistical analysis:}

The effect of hormonal eCG treatment (eCG) versus rearing-fasting program (r-FP) on the number of corpora lutea, the number of hemorrhagic follicles, the number of normal recovered embryos, the gestation duration, and the number of born alive, stillborn and weaned kits per donor doe were analyzed by a General Linear Model (SPSS version 16.0, SPSS Inc., USA, 2002). Also the effect of eCG $v s$ r-FP on estradiol-17 $\beta$ and leptin concentrations in serum was analyzed by a General Linear Model (SPSS version 16.0, SPSS Inc., USA, 2002). A Chisquare test (SPSS version 16.0, SPSS Inc., USA, 2002) was used to compare the effect of eCG $v s$ r-FP on receptivity rate, the recovery rate, the embryo donor rate, the blastocyst rate, the pregnancy rate and the kindling rate. A General Linear Model (SPSS version 16.0, SPSS Inc., USA, 2002) was used to analyze the effect of eCG $v s$ r-FP on the in vitro and in vivo productivity index.

\section{RESULTS}

The average receptivity rate of does was $62 \%$ (74/119). A significant increase in receptivity was observed in eCG group in comparison with the other groups (82 vs 50 and 59\%; eCG group vs r-FP and control groups, respectively, $\mathrm{P}<0.05$; data not shown in the tables).

The effect of eCG vs r-FPon ovulation and embryo recovery of donor does are shown in Tables (1) and (2). The number of corpora lutea and hemorrhagic follicles were significantly higher in eCG group (13.8 and 3.9) than in r-FP (9.1 and 0.9) or in control group (10.3 and 1.3) $(\mathrm{P}<0.05$, Table 1). The recovery rate was significantly higher $(\mathrm{P}<0.05$, Table 1) in both eCG and r-FP group $(38.7 \%$ and $64.1 \%$ ) when compared with control $(20.8 \%)$, but it was significantly higher in r-FP group than that in eCG group. The embryo donor rate was significantly higher for r-FP group compared to the control $(100 \%$ vs $42.9 \%$, respectively) and intermediate for eCG (77.8\%). No significant differences were observed in the number of normal embryos recovered per doe (6.1, 5.7 and 5.0 normal embryos in eCG, r-FP and control, respectively, Table 2). The rate of embryos recovered in blastocyst stage significantly $(\mathrm{P}<0.05)$ decreased in eCG group when compared with r-FP or control groups $(4.7 \%$ vs $60.0 \%$ or $53.3 \%$, respectively, Table 2 ).

The influence of eCG vs r-FP method on the reproductive performance of does are presented in Table (3). The pregnancy rate was significantly lower in does treated with eCG $(68.4 \%)$ than in r-FP does or in control (100\% pregnancy for both). The gestation duration was significantly higher in does treated with eCG (32.3 days) than in r-FP does (30.0 days) or in control (29.8 days) $(\mathrm{P}<0.05)$. The kindling rate was significantly higher $(\mathrm{P}<0.05$, Table 3$)$ in $\mathrm{r}-$ FP group $(87.5 \%)$ when compared with eCG group $(52.6 \%)$ and intermediate for control $(81.3 \%)$. The number of born alive and weaned kits significantly $(\mathrm{P}<0.05)$ decreased in eCG group $(4.1$ and 3.8 , respectively) in comparison with r-FP group (7.3 and 6.7, respectively) or control group (6.8 and 6.1, respectively), while the number of stillborn significantly increased in eCG group (0.8) when compared with other groups $(0.1$ for r-FP and 0.2 for control, Table 3).

Table 1. The number (mean \pm SEM) of corpora lutea, hemorrhagic follicles and recovery rate as affected by eCG treatment and rearing-fasting program

\begin{tabular}{lcccc}
\hline Treatments $^{1}$ & $\begin{array}{c}\text { Receptive } \\
\text { does }\end{array}$ & $\begin{array}{c}\text { Corpora lutea } \\
\text { LSM } \pm \text { S.E }\end{array}$ & $\begin{array}{c}\text { Hemorrhagic follicles } \\
\text { LSM } \pm \text { S.E }\end{array}$ & $\begin{array}{c}\text { Recovery rate } \\
\boldsymbol{\%}^{\circ}\end{array}$ \\
\hline Control & 7 & $10.3 \pm 0.6^{\mathrm{a}}$ & $1.3 \pm 0.3^{\mathrm{a}}$ & $20.8^{\mathrm{a}}$ \\
eCG & 9 & $13.8 \pm 1.2^{\mathrm{b}}$ & $3.9 \pm 0.7^{\mathrm{b}}$ & $38.7^{\mathrm{b}}$ \\
r-FP & 7 & $9.1 \pm 0.8^{\mathrm{a}}$ & $0.9 \pm 0.5^{\mathrm{a}}$ & $64.1^{\mathrm{c}}$
\end{tabular}

$\mathrm{LSM} \pm$ S.E.: least square means \pm standard error; $(n)$ : number of donor does; Values with different letters $(\mathrm{a}, \mathrm{b})$ in the same column are statistically different $(\mathrm{P}<0.05)$.

${ }^{1}$ Control: Does were fed ad libitum till first insemination; eCG: Does were injected 50IU eCG subcutaneously 60h before first insemination; r-FP: Does were fasted 3 days per week during rearing period till first insemination. 
Table 2. Embryo donor rate\%, number of normal embryos and blastocyst (mean \pm SEM) rate as affected by eCG treatment and rearing-fasting program

\begin{tabular}{lccc} 
Treatments $^{\mathbf{1}}$ & $\begin{array}{c}\text { Embryo donor rate } \\
(\%)(\mathbf{n})\end{array}$ & $\begin{array}{c}\text { Normal embryos }^{3} \\
(\text { LSM } \pm \text { S.E) }\end{array}$ & $\begin{array}{c}\text { Blastocyst rate }^{4} \\
(\%)\end{array}$ \\
\hline Control & $42.9^{\mathrm{a}}(3)$ & $5.0 \pm 1.2$ & $53.3^{\mathrm{b}}$ \\
eCG & $77.8^{\text {ab }}(7)$ & $6.1 \pm 1.0$ & $4.7^{\mathrm{a}}$ \\
r-FP & $100.0^{\mathrm{b}}(7)$ & $5.7 \pm 1.4$ & $60.0^{\mathrm{b}}$ \\
\hline
\end{tabular}

$\mathrm{LSM} \pm$ S.E.: least square means \pm standard error; $(n)$ : number of donor does; Values with different letters $(\mathrm{a}, \mathrm{b})$ in the same column are statistically different $(\mathrm{P}<0.05)$.

${ }^{1}$ Control: Does were fed ad libitum till first insemination; eCG: Does were injected 50IU eCG subcutaneously 60h before first insemination; r-FP: Does were fasted 3 days per week during rearing period till first insemination.

${ }^{2}$ Embryo donor rate: percentage of donor does with at least one normal embryo respect to ovulating does.

${ }^{3}$ Normal embryos: number of normal embryos recovered in does with at least one normal embryo.

${ }^{4}$ Blastocyst rate: percentage of embryos in blastocyst stage recovered in does with at least one normal embryo.

Table 3. Reproductive performance of rabbit does as affected by eCG treatment and rearing-fasting program

\begin{tabular}{lccccccc}
\hline Treatments & $\begin{array}{c}\text { Receptive } \\
\text { does }\end{array}$ & $\begin{array}{c}\text { Pregnancy } \\
\text { Rate } \\
\%(\mathbf{n})\end{array}$ & $\begin{array}{c}\text { Gestation } \\
\text { days } \\
(\text { LSM } \pm \text { S.E) }\end{array}$ & $\begin{array}{c}\text { Kindling } \\
\text { rate }(\%)(\mathbf{n})\end{array}$ & $\begin{array}{c}\text { Alive born } \\
(\text { LSM } \pm \text { S.E) }\end{array}$ & $\begin{array}{c}\text { Stillborn } \\
(\mathbf{L S M} \pm \\
\text { S.E) }\end{array}$ & $\begin{array}{c}\text { weaned } \\
\text { kits } \\
(\text { LSM } \pm \text { S.E) }\end{array}$ \\
\hline Control & 16 & $100.0^{\mathrm{b}}(16)$ & $29.8 \pm 0.1^{\mathrm{a}}$ & $81.3^{\mathrm{ab}}(13)$ & $6.8 \pm 0.6^{\mathrm{b}}$ & $0.2^{2} \pm 0.2^{\mathrm{a}}$ & $6.1 \pm 0.5^{\mathrm{b}}$ \\
eCG & 19 & $68.4^{\mathrm{a}}(13)$ & $32.3 \pm 0.2^{\mathrm{b}}$ & $52.6^{\mathrm{a}}(10)$ & $4.1 \pm 0.6^{\mathrm{a}}$ & $0.8 \pm 0.2^{\mathrm{b}}$ & $3.8 \pm 0.6^{\mathrm{a}}$ \\
r-FP & 16 & $100.0^{\mathrm{b}}(16)$ & $30.0 \pm 0.1^{\mathrm{a}}$ & $87.5^{\mathrm{b}}(14)$ & $7.3 \pm 0.6^{\mathrm{b}}$ & $0.1 \pm 0.2^{\mathrm{a}}$ & $6.7 \pm 0.5^{\mathrm{b}}$ \\
\hline
\end{tabular}

$\mathrm{LSM} \pm$ S.E.: least square means \pm standard error; $(n)$ : number of donor does; Values with different letters $(\mathrm{a}, \mathrm{b})$ in the same column are statistically different $(\mathrm{P}<0.05)$.

${ }^{1}$ Control: Does were fed ad libitum till first insemination; eCG: Does were injected 50IU eCG subcutaneously 60h before first insemination; r-FP: Does were fasted 3 days per week during rearing period till first insemination.

Results of hormonal profile ( $\mathrm{E}_{2}$ and leptin concentrations in serum) for does as affected by eCG treatment or r-FP application are shown in Figures (1) and (2). Hormonal (eCG) and r-FP methods markedly increased serum $\mathrm{E}_{2}$ concentration compared with control, but $\mathrm{E}_{2}$ concentration in r-FP group was significantly higher than that in eCG group (6.60 vs 5.52 vs $4.09 \mathrm{pg} / \mathrm{ml}$ for r-FP vs eCG $v s$ control, respectively, $\mathrm{P}<0.05$, Figure 1). In a same way, leptin showed a significant $(\mathrm{P}<0.05)$ higher concentration in serum of r-FP rabbits $(1.63 \mathrm{ng} / \mathrm{ml})$ than that in eCG rabbits $(1.30 \mathrm{ng} / \mathrm{ml})$ or in control rabbits (1.22 ng/ml) (Figure 2).

No significant differences were observed between groups in the in vitro productivity index, however, it tended to increase in eCG and r-FP groups than in control group (4.9, 5.7 and 2.0 for eCG, r-FP and control, respectively, $\mathrm{P}=0.073$, data not shown in tables). On the other hand, the in vivo productivity index significantly decreased in eCG group than r-FP and control groups (2.5 vs 5.9 and 4.9 for eCG $v s$ rFP and control, respectively, $\mathrm{P}<0.05$, data not shown in tables).

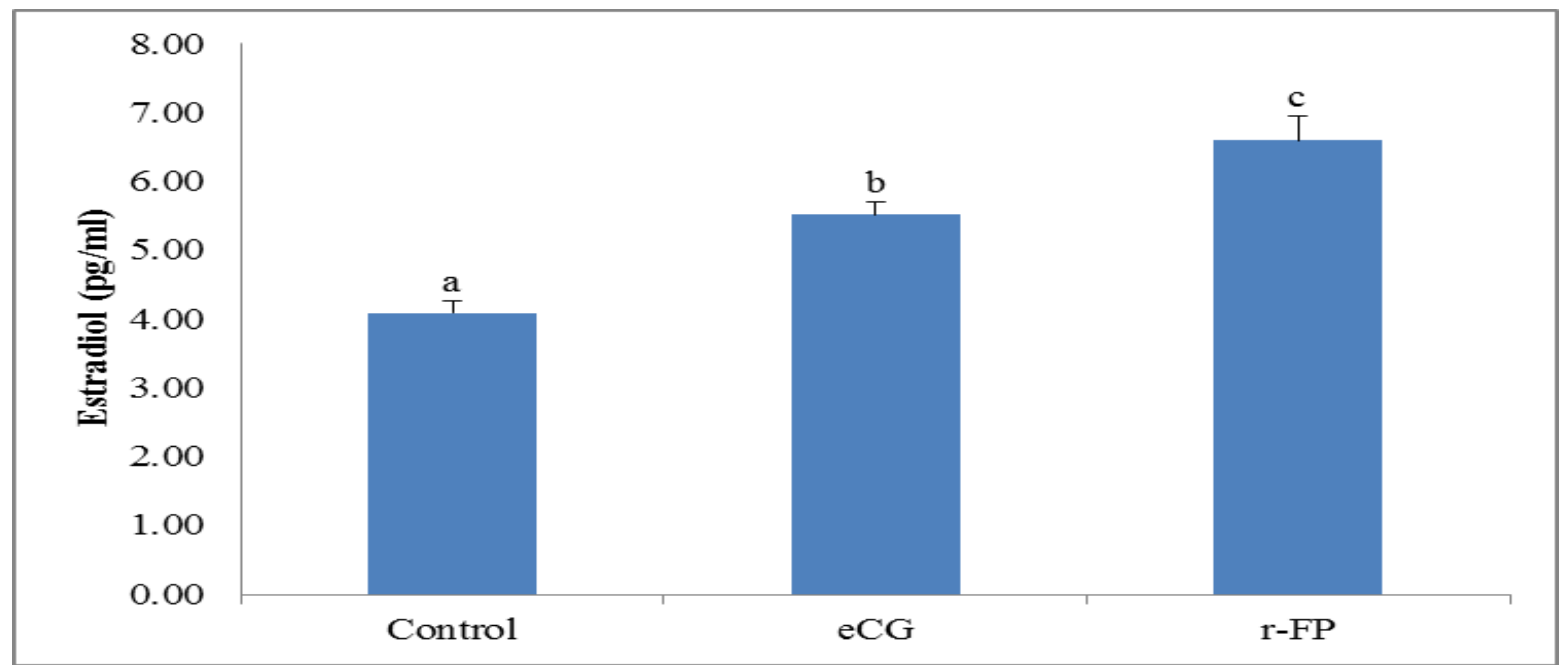

Figure 1. The serum concentration of estradiol-17 $\beta$ in rabbit receptive females at the time of artificial insemination; Bares with different letters $(\mathbf{a}, \mathrm{b}, \mathrm{c})$ are statistically different $(\mathrm{P}<0.05)$ 


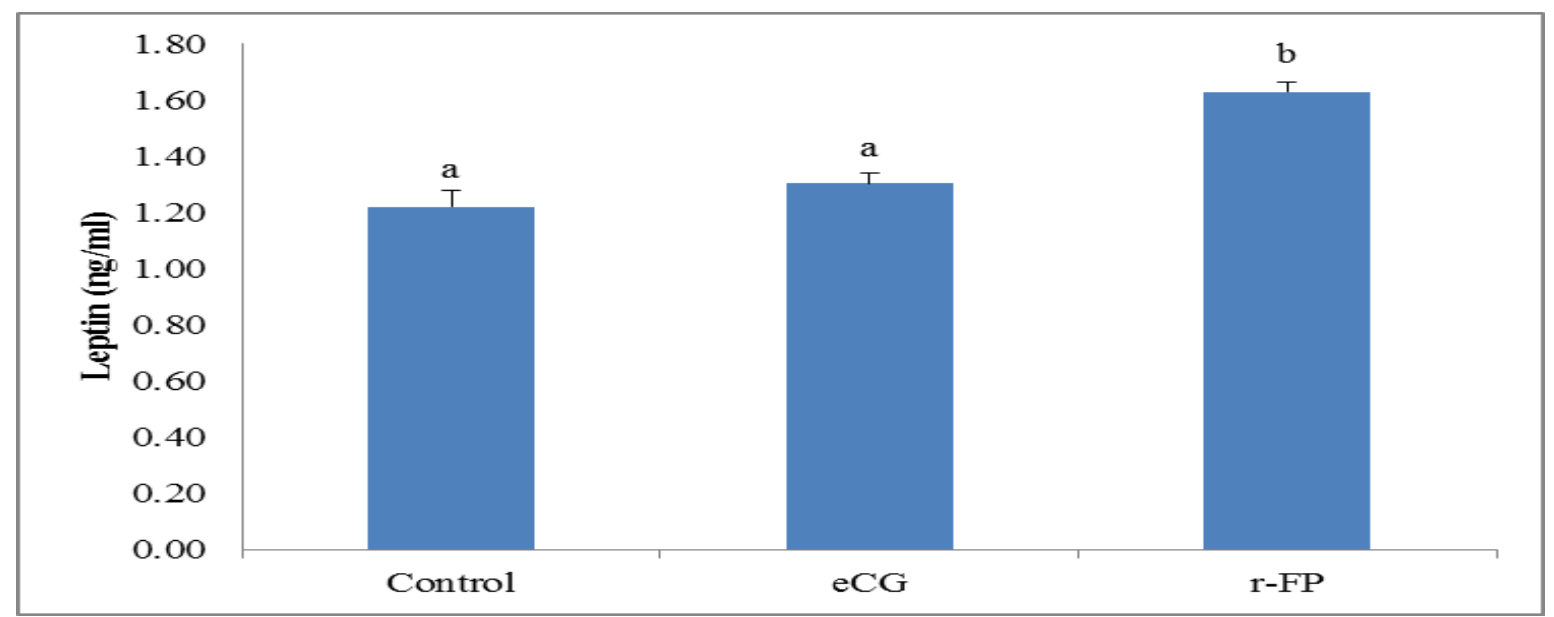

Figure 2. Serum concentration of leptin in rabbit receptive females at the time of artificial insemination; Bares with different letters $(\mathbf{a}, \mathbf{b})$ are statistically different $(\mathbf{P}<\mathbf{0 . 0 5})$

\section{DISCUSSION}

In previous works, we proved that treatment with $50 \mathrm{IU}$ of eCG hormone subcutaneously $60 \mathrm{~h}$ before the first insemination (eCG group) was still favored to induce superovulation in rabbit females with a minimum deleterious effects on reproduction and embryo development (Mehaisen et al., 2004 and Mehaisen et al., 2005). In the present study, we were mainly interested in verifying changes in reproductive performance, embryo recovery and related hormonal profile when the hormonal eCG treatment was replaced with a fasting program during rearing period followed by one-week nutritional flushing before insemination (r-FP) as an alternative bio-stimulation method in rabbit does.

The hormonal eCG treatment significantly increased the receptivity rate and the number of corpora lutea of rabbit does in comparison with r-FP or control group. However, this increase in ovulation sites in the ovary of eCG-treated does was accompanied with significant increase in the number of hemorrhagic follicles (Table 1), mainly due to the high dose of eCG (50IU) used in this study as occurred in previous studies (Mehaisen et al., 2005). On the contrary, observations of Theua- Clément et al. (2008b) did not confirm the increase in the number of hemorrhagic follicles after eCG treatment, but they used lower doses (8-25 IU). We observed that eCG treatment did not improve the embryo recovery rate, while it significantly increased in r-FP group when compared with control (Table 1). On the other hand, there were no differences between groups in the number of normal embryos recovered per doe (6.1, 5.7 and 5.0 normal embryos in eCG, r-FP and control, respectively, (Table 2). However, $100 \%$ of receptive does from r-FP group were able to produce normal embryos, while it was only $77.8 \%$ of receptive does treated with eCG and only $42.9 \%$ of control group (Table 2). In addition, $58.4 \%$ of recovered embryos from r-FP does were obtained in early blastocyst stage versus $3.4 \%$ in eCG does. These results agree with authors who observed a negative effect of high doses of eCG (>50IU) on in vitro embryo production in rabbits (Tsiligianni et al., 2004, Mehaisen et al., 2004, Mehaisen et al., 2005 and Mehaisen et al., 2006), but values obtained in the present study were often low compared with that obtained by these last authors. In a previous study by Mehaisen et al. (2005) who compared rabbit does treated with 50IU eCG with non-treated does, they did not find differences in the number of normal recovered embryos per doe (8.2 and 6.5, respectively) or in the embryo donor rate $(75.9$ and $68.4 \%$, respectively). Another study by Bonanno et al. (2004) compared rabbit does fed ad libitum with does received $75 \%$ restricted feeding during rearing followed by flushing 10 days before $\mathrm{AI}$, and they found an improvement in prolificacy of restricted females (90\% vs 60\%) embryo donor rate and $7.2 \mathrm{vs}$ 4.7 normal embryos per doe at 5 days after AI for restricted $v s$ ad libitum females, respectively. The in vitro productivity index calculated in this study indicated that the global efficiency of embryo production in receptive does tended to increase $(\mathrm{P}=0.073)$ in eCG (4.9) and r-FP (5.7) groups than control (2.0). These findings and our results of embryo recovery evidenced that r-FP method for estrus synchronization of rabbit does could be preferred to produce normal embryos with high developmental competence from the maximum number of donors.

Compared to eCG treated does, r-FP and control does groups showed significantly higher pregnancy rate, number of born alive and number of weaned kits. The kindling rate in r-FP group was significantly higher than eCG group, but intermediate in the control group. In opposite way, a significant lower gestation duration and number of stillborn was recorded for r-FP and control groups than eCG group (Table 3). Other studies reported higher performance (fertility rate, kindling rate, and litter size and weight at weaning) in does raised on restricted feeding compared to those raised on ad libitum feeding (Maertens, 1992, Nizza et al., 1997 and Eiben et al., 2001). In the present study, does of r-FP group were received $57 \%$ of feed consumed by control and eCG groups during rearing period, however, we observed 
that the body weight (BWt) and feed intake (FI) at the time of insemination in r-FP group were higher than the other groups (2830 vs $2770 \mathrm{~g} \mathrm{BWt}$ and 223 vs $185 \mathrm{~g}$ /doe/day FI for r-FP group vs both control and eCG groups, respectively; (data not shown in tables). This consequently improved the reproductive performance of r-FP does to at least the same level of control does fed ad libitum during rearing or sometimes higher (Ashworth et al., 1999, Lozano et al., 2003, Tumova et al., 2003 and Gyovai, 2006). While we found that $50 \mathrm{IU}$ eCG treatment negatively $(\mathrm{P}<0.05)$ affect the reproductive performance of does maybe because they produce oocytes and embryos with structural abnormalities and low developmental competence (Tsiligianni et al., 2004, Mehaisen et al., 2006 and Arias-Álvarez et al., 2010). The negative effect of eCG on globlal reproduction efficiency was confirmed in our study when high doses (50 IU) were applied (in vivo productivity index was 2.5 vs 5.9 and 4.9 for eCG vs r-FP and control, respectively, $\mathrm{P}<0.05)$. However, Theua- Clément et al. (2008a) concluded that lower doses of eCG (8-25 IU) makes possible to gain $20 \%$ more weaned rabbits per AI (5.9 vs 7.1 for control vs eCG treatments).

Generally, previous works reported a direct correlation of oestradiol concentration in plasma with vulva color and receptivity of rabbit females (Ubilla and Rebollar, 1995, Rodriguez de Lara and Fallas, 1999 and Manal, 2010). Our results also indicated that hormonal eCG treatment markedly $(\mathrm{P}<0.05)$ increased receptivity of females to $82 \%$ compared with $59 \%$ in control (data not shown) in a coincidence with significant increase in serum $\mathrm{E}_{2}$ concentration $(5.52 \mathrm{pg} / \mathrm{ml}$ for eCG $v s 4.09 \mathrm{pg} / \mathrm{ml}$ for control, Figure 1). On the other hand, a significant increase in $\mathrm{E}_{2}$ level was recorded for r-FP group $(6.60 \mathrm{pg} / \mathrm{ml})$ when compared with the eCG group or control (Figure 1). The increased $\mathrm{E}_{2}$ level of $\mathrm{r}-\mathrm{FP}$ group could be explained by the refreshment of the hypothalamus-pituitary-ovary cycle due to the increased amount of energy available for the doe during nutritional flushing immediately before AI (Theau-Clément et al., 1998, Rodriguez de Lara et al., 2000, Gómez et al., 2004 and Manal, 2010). On the contrary, the down regulation of many nutritional mediators due to reduced feed intake may directly influence the steroidogenic capability of ovarian follicles through gonadotropin independent mechanism (Brecchia et al., 2006), which resulted in lower $\mathrm{E}_{2}$ levels in both eCG and control groups.

Leptin, an important hormone corresponds with the nutritional condition and reproduction status of domestic animals, has also been studied in the current work. We found that serum leptin concentration at the time of AI was significantly higher in r-FP group $(1.63 \mathrm{ng} / \mathrm{ml})$ than in eCG $(1.30 \mathrm{ng} / \mathrm{ml})$ and control groups $(1.22 \mathrm{ng} / \mathrm{ml}$ ) (Figure 2). Our results are consistent with that recently recorded in rabbits by (Daoud et al., 2012), who stated that serum leptin concentration reached $1.67 \mathrm{ng} / \mathrm{ml}$ in does received $70 \%$ of control diet vs $1.27 \mathrm{ng} / \mathrm{ml}$ in control does after refeeding. Leptin increase in restricted groups is almost related to its role in signaling the metabolic state of the animal and in the regulation of appetite (Woods et al., 2003), especially when does moved from feed restriction to ad libitum refeeding (Marie $e t$ al., 2001 and Rebollar et al., 2008), as occurred in our study one week before AI. Brecchia et al. (2006) noted that within $1 \mathrm{~h}$ after realimentation of restricted rabbit does, glucose and insulin quickly increased due to the sudden shift from fat to carbohydrate metabolism, which in turn might have mediated the leptin response of rabbits to realimentation (Walker et al., 2005). Therefore, the success of fasting program during rearing period of rabbit does to synchronize their estrus cycle with effective reproduction mainly depends on nutritional flushing or ad libitum refeeding before insemination (TheauClément, 2000). On the other hand, the suggested role of leptin in steroidogenesis of pre- and postovulatory follicles (Zerani et al., 2004) is confirmed in our study since the high level of serum leptin was accompanied with high level of serum $\mathrm{E}_{2}$ in $\mathrm{r}$-FP group. Such increase in leptin and estradiol concentrations in r-FP does could modulate ovarian physiology through its receptors detected in follicles, oocytes and oviducts (Zerani et al., 2004, Brecchia et al., 2006 and Arias-Álvarez et al., 2010), inducing an obvious improvement in embryo recovery, donor rate, blastocyst rate and pregnancy rate in this study.

In conclusion, although the use of eCG in high doses appears to ensure sexual receptivity and abundance source of normal embryos in receptive donor does, it shows a negative consequence on the productivity and final yield of weaned rabbits. Rearing-fasting program followed by feed flushing before insemination could be applied as a biostimulation method for estrus synchronization of rabbit does, maintaining the global in vitro productivity of embryos and in vivo productivity of weaned rabbits at acceptable practical levels. Before being applied, these results should be confirmed using a higher number of observations, lower doses of eCG (20 IU). It could be interesting too to measure the efficiency of that method on several reproductive cycles.

\section{REFERENCES}

Alabiso M., A. Bonanno, M. L. Alicata and B. Portalano, 1994. Trattamento "differenziato" con PMSG su coniglie inseminate artificialmente. Rivista di coniglicoltura, 31: 25 -30 .

Arias-Álvarez M., R. M. García-García, L. TorresRovira, A. González-Bulnes, P. G. Rebollar and P. L. Lorenzo, 2010. Influence of hormonal and nonhormonal estrus synchronization methods on follicular and oocyte quality in primiparous lactating does at early postpartum period. Theriogenology, 73: $26-35$.

Ashworth C. J., C. Antipatis and L. Beattie, 1999. Effects of pre-and post-mating nutritional status on hepatic function, progesterone concentration, uterine protein secretion and embryo survival in 
Meishan pigs. Reproduction Fertility Development, 11: 67 - 73 .

Boiti C., 2004. Underlying physiological mechanisms controlling the reproductive axis of rabbit does. The $8^{\text {th }}$ World Rabbit Congress, Puebla, Mexico, pp 186 - 206.

Bonanno A., F. Mazza, A. DiGrigoli and M. L. Alicata, 2004. Effects of restricted feeding during rearing, combined with a delayed first insemination, on reproductive activity of rabbit does. The $8^{\text {th }}$ World Rabbit Congress, Puebla, Mexico, pp $224-230$.

Brecchia G., A. Bonanno, G. Galeati, C. Dallaglio, A. Di Grigoli, F. Parrillo and C. Boiti, 2004. Effects of short- and long-term fasting on the ovarian axis and reproductive performance of rabbits does. The $8^{\text {th }}$ World Rabbit Congress, Puebla, Mexico, pp 231-237.

Brecchia G., A. Bonanno, G. Galeati, I. C. Federic, M. Maranesi, A. Gobbetti, M. Zerani and C. Boiti, 2006. Hormonal and metabolic adaptation of fasting: effects on the hypothalamicpituitary-ovarian axis and reproductive performance of rabbit does. Domestic Animal Endocrinology, 31: 105 - 122.

Castellini C., 1996. Recent advances in rabbit artificial insemination. The $6^{\text {th }}$ World Rabbit Congress, Brescia, Italy, Volume 2: pp $13-26$.

Cunningham M. J., D. K. Clifton and R. A. Steiner, 1999. Leptin's actions on the reproductive axis: perspectives and mechanisms. Biology of Reproduction, 60: 216 - 222.

Daoud Niveen M., Karima F. Mahrous and Omaima H. Ezzo, 2012. Feed restriction as a biostimulant of the production of oocyte, their quality and GDF-9 gene expression in rabbit oocytes. Animal Reproduction Science, 136: $121-127$.

Eiben C., K. Kustos, A. Kenessey, G. Virag and Z. Szendro, 2001. Effect of different feed restrictions during rearing on reproduction performance in rabbit does. World Rabbit Science, 9: 9 - 14 .

Fortun-Lamothe L., 1998. Effects of pre-mating energy intake on reproductive performance of rabbit does. Animal Science, 66: 263 - 269.

Gómez R. B., P. C. M. Becerril, H. G. Torres, M. A. Pro and R. Rodríguez De Lara, 2004. Relationship among feeding level, change of cage and fasting with vulva color and sexual receptivity in New Zealand White and Californian nulliparous does. The $8^{\text {th }}$ World Rabbit Congress, 7-10 September, Puebla, Mexico, pp $270-275$.

Gosalvez L. F., J. M. R. Alvariño, P. Díaz and M. Tor, 1995. Influence of age, stimulation by PMSG or flushing on the ovarian response to LHRH in young rabbit females. World Rabbit Science, 2: $41-45$.

Gyovai M. H., 2006. Effect of nutrient supply during rearing and age at first insemination on the performance of rabbit does. PhD dissertation, University of Kaposvár, pp 96.
Lozano J. M., P. Lonergan, M.P. Boland and D. OфCallaghan, 2003. Influence of nutrition on the effectiveness of superovulation programmes in ewes: effect on oocyte quality and postfertilization development. Reproduction, 125: $543-553$

Luzi F., S. Barbieri, C. Lazzaroni, C. Cavani, M. Zecchini and C. Crimella, 2001. Effets de l'addition de propylène glycol dans l'eau de boisson sur les performances de reproduction des lapines. World Rabbit Science, 9: 15 - 18.

Maertens L., 1992. Rabbit nutrition and feeding: A review of some recent developments. Journal of Applied Rabbit Research, 15: 889 - 913.

Maertens L., 1998. Effect of flushing, mother-litter separation and PMSG on the fertility of lactating does and the performance of their litter. World Rabbit Science, 6 (1): 185 - 190.

Manal A. F., 2010. Flushing or doe relocation as biostimulation methods for improvement of sexual behaviour and performance of multiparous rabbit doe after a summer resting period. World Rabbit Science, 18: $151-158$.

Marie M., P. A. Findlay, L. Thomas and C. L. Adam, 2001. Daily patterns of plasma leptin in sheep: effects of photoperiod and food intake. Journal of Endocrinology, 170: 277 - 286.

Mehaisen G. M. K., J. S. Vicente and R. Lavara, 2004. In vivo embryo recovery rate by laparoscopic technique from rabbit does selected for growth rate. Reproduction in Domestic Animal, 39: 347 - 51.

Mehaisen G. M. K., J. S. Vicente, R. Lavara, and M. P. Viudes de Castro, 2005. Effect of eCG dose and ovulation induction treatments on embryo recovery and in vitro development postvitrification in two selected lines of rabbit does. Animal Reproduction Science, 90: 148 - 75.

Mehaisen G. M. K., M. P. Viudes de Castro, J. S. Vicente and R. Lavara, 2006. In vitro and in vivo viability of vitrified and non-vitrified embryos derived from eCG and FSH treatment in rabbit does. Theriogenology, 65: 1279 1291.

Nizza A., C. Dimeo and L. Esposito, 1997. Influence of the diet used before and after the first mating on reproductive performance of rabbit does. World Rabbit Science, 5: 107 - 110.

Rebollar P. G., P. Millán, B. Schwarz, N. Pereda, M. Marco, P. L. Lorenzo and N. Nicodemus, 2008. Young rabbit does fed with fibrous diet during rearing: serical and productive parameters. The $9^{\text {th }}$ World Rabbit Congress, 10-13 June, Verona, Italy, pp $431-435$.

Rodriguez de Lara R. and L. M. Fallas, 1999. Environmental and physiological factors influencing kindling rates and litter size at birth in artificially inseminated doe rabbits. World Rabbit Science, 7: $191-196$.

Rodríguez De Lara R., 2002. Control de la reproducción en la coneja. 2do Congreso de Cunicultura de Las Américas, pp 247-258. 
Rodríguez De Lara R., L. M. Fallas and S. R. Rangel, 2000. Influence of body live weight and relocation on kindling rate and prolificacy in artificially inseminated nulliparous doe rabbits. The $7^{\text {th }}$ World Rabbit Congress, Valencia, Spain, Volume A: pp $251-257$.

Rommers J. M., B. Kemp, R. Meijerhof and J. P. T. M. Noordhuizen, 2001. The effect of litter size before weaning on subsequent body development, feed intake, and reproductive performance of young rabbit does. Journal of Animal Science, 79: 1973 - 1982.

Theau-Clément M., 2000. Advances in biostimulation methods applied to rabbit reproduction. The $7^{\text {th }}$ World Rabbit Congress, Valencia, Spain, Volume A: pp $61-79$.

Theau-Clément M., 2007. Preparation of the rabbit doe to insemination: A review. World Rabbit Science, 15: 61-80.

Theau-Clément M., C. Castellini, L. Maertens and C. Boiti, 1998. Biostimulations applied to rabbit reproduction: Theory and practice. World Rabbit Science, 6: 179 - 184.

Theau-Clément M., F. Lebas and J. Falières, 2008b. Influence of different eCG doses on the rabbit doe ovary response, fertilising aptitude and embryo development. World Rabbit Science, 16: $73-79$.

Theau-Clément M., F. Lebas, C. Boiti, G. Brecchia and P. Mercier, 2008a. Influence of different eCG doses on sexual receptivity and productivity of rabbit does. World Rabbit Science, 16: $65-72$.

Theau-Clément M., F. Lebas, J. F. Beckers and P. Drion, 2008c. Evolution of anti-eCG antibodies in response to eCG doses and number of injections. Relationship with productivity of rabbit does. Animal, 2 (5): 746 - 751.
Tsiligianni T., A. Saratsi, U. Besenfelder, A. Anastasiadis, E. Vainas, P. Saratsis and G. Brem, 2004. The use of cytological examination of vaginal smears (CEVS) in the selection of rabbits for superovulation. Theriogenology, 61: $989-95$.

Tumova E., V. Skrivanova and M. Skriran, 2003. Effect of restricted feeding time and quantitative restriction in growing rabbits. Arch Geflugel Kunde, 67 (4): 182 - 190.

Ubilla E. and P. G. Rebollar, 1995. Influence of the post-partum day on plasma estradiol-17 beta levels, sexual behaviour and conception rate, in artificially inseminated lactating rabbits. Animal Reproduction Science, 38: 337 - 344.

Viudes De Castro M. P., C. Cortell, E. Moce, F. Marco-Jimenez, T. Joly and J. S. Vicente, 2009. Effect of recombinant gonadotropins on embryo quality in superovulated rabbit does and immune response after repeated treatments. Theriogenology, 72: $655-662$.

Walker C. G., J. M. Bryson, K. S. Bel-Anderson, D. P. Hancock, G. S. Denyer and I. D. Caterson, 2005. Insulin determines leptin responses during a glucose challenge in fed and fasted rats. International Journal Obstetrics, 29: 398 405.

Woods S. C., R. J. Seeley, D. G. Baskin and M. W. Schwarts, 2003. Insulin and the blood-brain barrier. Current Pharmaceutical Design, 10: 795 -800 .

Zerani M., C. Boiti, D. Zampini, G. Brecchia, C. DallAglio, P. Ceccarelli and A. Gobbetti, 2004. $\mathrm{Ob}$ receptor in rabbit ovary and leptin in vitro regulation of corpora lutea. Journal of Endocrinology, 183: 279 - 288.

\section{تأثير المعاملة بهرمون eCG مقابل برنامج للتصويم خلال فترة التربية على استخلاص الأجنة والأداء التناسلي

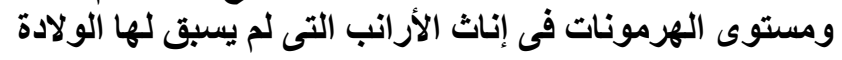 جمال محمد كامل محيسن، أحمد عثمان عباس

كان الهدف من هذه الدراسة هو تحديد تأثير طريقة تزامن الثبق عن طريق المعاملة الثاء بهرمون eCG مقابل برنامج تصويم أثناء فترة التربية

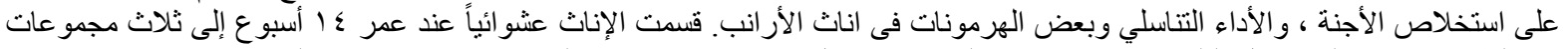

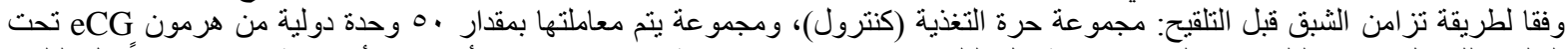

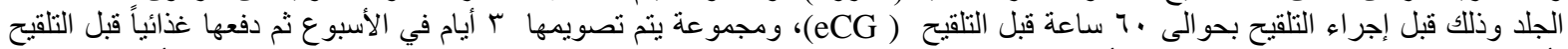

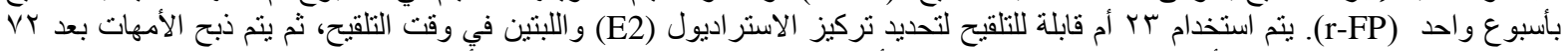

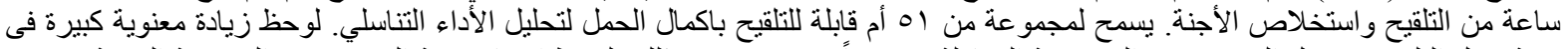

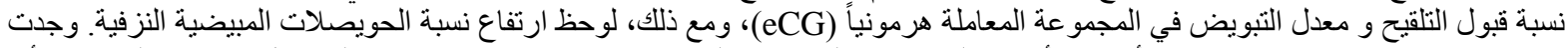

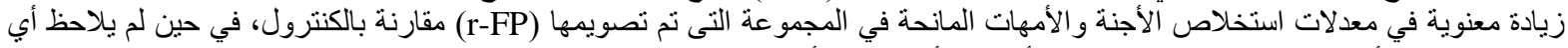

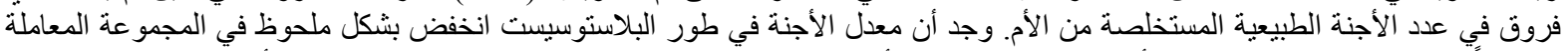

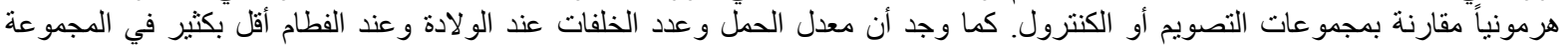

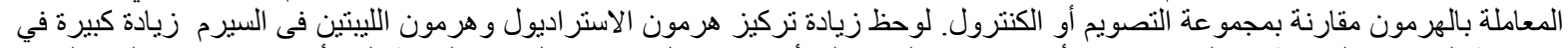

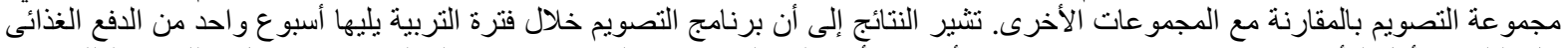

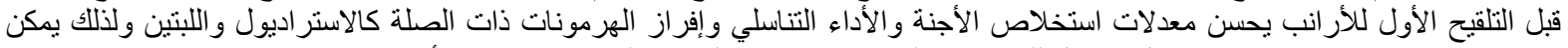

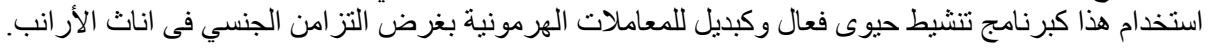

